\title{
Las crónicas de los diarios generalistas y deporti- vos de la final FIFA World Cup (South Africa)
}

\author{
Francisco GARCÍA GARCÍA \\ Universidad Complutense de Madrid \\ fghenche@g.mail.com \\ Isidoro ARROYO ALMARAZ \\ Universidad Rey Juan Carlos de Madrid \\ isidoro.arroyo@urjc.es
}

Recibido: 04/06/2012

Aceptado: 30/10/2012

\section{Resumen}

Se analizan seis crónicas deportivas, tres de periódicos generalistas y tres de deportivos relacionadas con la final España-Holanda del Campeonato Mundial de Sudáfrica. Se comparan sus lenguajes atendiendo a sus léxicos: bélico, jurídico, lúdico, mágico y social; a las agrupaciones de palabras: palabra, locución o frase hecha ; y a los aspectos referenciales y metafóricos del discurso. Se concluye que los léxicos están presentes en todo el corpus, destacando el bélico. Existe una relación entre el tamaño de una crónica y la presencia de los léxicos en los diarios deportivos, pero no en los generalistas. Se utiliza más el discurso referencial que el metafórico. Se usan más palabras que locuciones y frases. Y más locuciones $\mathrm{y}$ frases en el discurso metafórico que en el referencial.

Palabras clave: Crónicas deportivas, ámbitos léxicos, Campeonato Mundial de Fútbol.

\section{Lexical Analysis of the Chronicles of the Spanish Newspapers Covering the FIFA World Cup Final (South Africa)}

\begin{abstract}
Six sports chronicles were analyzed, three from general newspapers and three from sports press, related to the FIFA World Cup Final (South Africa). Each sample was analyzed based on the used lexicon (war, law, recreation, magic and society), the word grouping (spare words, phrases and set phrases), and the referential and metaphorical aspects of the speech. The conclusion was that all the lexicons under analysis were evenly blended throughout each chronicle except for the war language, which was used more extensively. Additionally, a relationship was discovered between the size of a chronicle and the usage of the lexicons in the chronicles from the sports newspapers. That same relationship did not exist in the case of the general press. Also, the study concludes that the referential speech prevailed over the metaphorical. Finally, spare words were found more often in the samples than other forms of word grouping. This statement is a realization of the previous one, as phrases were more popular in the methaphorical speech.
\end{abstract}

Keywords: Sports chronicle, sports press, lexicon, FIFA World Cup.

\section{Referencia normalizada}

GARCÍA GARCÍA, Francisco y ARROYO ALMARAZ, Isidoro (2013): "Las crónicas de los diarios generalistas y deportivos de la final FIFA World Cup (South Africa)". Estudios sobre el mensaje periodistico. Vol. 19, Núm. 1, págs.: 131-146. Madrid, Servicio de Publicaciones de la Universidad Complutense.

Sumario: 1.Introducción. 2. Fuentes y estado de la cuestión; 2.1. Los tipos de léxicos; 2.1.1. El léxico bélico; 2.1.2. El léxico jurídico; 2.1.3. El léxico lúdico; 2.1.4. El léxico mágico; 2.1.5. El léxico social. 3. Metodología; 3.1. Objetivos; 3.2. Hipótesis; 3.3. Técnicas metodológicas; 3.3.1. Corpus de análisis. 4. Análisis de los datos; 4.1. Análisis del léxico de las crónicas de los tres diarios deportivos; 4.2. Análisis del léxico de las tres crónicas de los diarios generalistas. 5. Conclusiones. 6. Discusión. 7. Referencias bibliográficas. 


\section{Introducción}

El fútbol es en la actualidad un referente social que se integra profundamente dentro de la cultura global. Es, tal vez, uno de los espectáculos más importes de la industria de la comunicación. Como fenómeno de la cultura de masas articula una retórica informativa y expresiva capaz de dar información y a la vez enardecer a los espectadores y a los lectores de las crónicas futbolísticas. A pesar de que los espectadores hayan podido ver en directo o por televisión u oido a través de la radio o seguido a través de Internet un partido de fútbol, leen las cróncias deportivas en los periódicos generalistas y deportivos buscando, no sólo información u opinión, sino motivos para justificar las razones y los afectos que den sentido a su conducta como seguidores de su equipo con el que se identifican y donde proyectan deseos, afectos, emociones, esperanzas, ilusiones, como un instrumento más de la alienación. Es un tema recurrente en congresos y seminarios, como lo ha sido en el VII Seminario de Lengua y Periodismo (10-11/05/2012) que se ha celebrado en San Millán de la Cogolla, destacando el valor de uso del español por los periodistas deportivos por su capacidad para crear expresiones nuevas en crónicas y reportajes que son géneros interpretativos que construyen realidad social a través de la información y su construcción retórica, como bien indica M. J. Casals (2004). "Los artículos sobre deportes hacen referencia a modelos sobre política deportiva y modelos de deportistas. Pero sobre todo reflexionan acerca del fútbol como significado social".

El lenguaje del fútbol se inscribe en el uso cotidiano del lenguaje común, así como de un lenguaje cada vez más particular y más específico pero que, dada su propia naturaleza y la finalidad pragmática que posee, se utiliza de modo referencial o metafórico. Lo que importa es transmitir al lector una información, al tiempo que una emoción, un convencimiento de la belleza, la estrategia, la espectacularidad, el valor y la respuesta de los aficionados atraídos por los ámbitos espacio-temporales del juego que ejecutan veintidós jugadores con un único objetivo, ganar el partido y la competición. Cada periodista va generando, a través de su creatividad y expresividad en el lenguaje, un estilema de autor, una forma libre de expresión, una estilística determinada que, como dice Eduardo Santa Cruz (2011: 656) "tendría un sólo límite (...) que se manifiesta con similar importancia en el plano expresivo, el cual debe someterse a las exigencias comunicativas, a la presencia heterogénea del lector, en sentido amplio. Así, el estilo de la crónica ha de ser claro, sencillo, conciso; revelador de un contenido objetivo que se comunica a alguien. En ese marco, valen todos los recursos estilísticos y retóricos. La única exigencia que fluye del marco es la claridad comunicativa en función de un público".

Cada género exige un tipo de discurso diferente en atención al contenido del mensaje, a las leyes pragmáticas de producción textual y de recepción de los lectores y a su finalidad comunicativa. Cada género, a su vez, tiene una nómina específica de periodistas que van dejando sus impronta en la construcción narrativa del género. Así pues nos encontramos con que género, estilema de autor y medio periodístico generan modos expresivos que constituyen una forma de reconocimiento de autor y una forma de especificidad discursiva. En el caso de la crónica de fútbol, este lenguaje específico y particular ha sido definido, entre otros autores, por Gómez Torrego (2010: 
151) como jerga futbolística que "no se caracteriza solo por tener un léxico más o menos críptico que es lo fundamental de las jergas (sino)... porque presenta rasgos gramaticales idiosincrásicos"; y por Mapelli (2010:159) como un lenguaje que "se distingue por una serie de expresiones que se insertan en un discurso que posee una gran fuerza evocadora y que asegura el éxito de la comunicación con el público" y que van construyendo un modelo regido por las expresiones que más éxito tienen, como dice el mismo autor (Mapelli, 2004:171) el lenguaje periodístico del fútbol cuyo sentido global "no deriva siempre de la suma del significado de sus componentes (sino) que las fórmulas más frecuentes se repiten con regularidad y de las que se han apropiado los jugadores y los aficionados". El periodista informa y al informar tienen que hacer referencia a los acontecimientos que se están produciendo en el partido, por lo que la crónica es un género informativo. Sin embargo el concepto de crónica lleva también en una cierta medida la intepretación, por lo tanto es algo más que información pero menos que un reportaje interpretativo. La interpretación tiene como base los hechos y los acontecimientos y sobre ellos es sobre lo que se ejerce la valoración de los mismos. Muchos autores coinciden en que un elemento distintivo de la crónica sería justamente la interpretación o valoración de los hechos que en ella se narran (Santa Cruz, 2011; Castañón, 1993; Medina, 2005; Santamaría, 1995).

Construye una historia con una referencialidad relacionada con las acciones, los espacios, los tiempos que transita el colectivo de jugadores que componen un equipo de fútbol y que puede girar en torno a un personaje, a una estrella o ser solo el resultado de un alma colectiva.

El equipo es entonces el personaje colectivo, pero por encima de todo, un partido de fútbol es un duelo entre oponentes, una lucha que se ofrece como espectáculo a unos espectadores que asumen los colores, los líderes y la historia de su equipo. El periodista se tendrá que centrar en la transmisión de esa historia, transmitir los hechos, los elementos referenciales, pero la forma en que se expresa incluye un componente metafórico. El periodista utiliza unos códigos expresivos ricos en construcción retórica que comparte con sus lectores. La belleza expresiva se alimenta de tópicos, de construcción retórica muy especialmente trópica que alienta la expresividad con una imaginación verbal que motivará respuestas emotivas de los lectores, trasunto épico del resultado de una victoria o de una derrota.

\section{Fuentes y estado de la cuestión}

Las crónicas deportivas de fútbol son un espacio discursivo donde se dan cita distintos ámbitos semánticos referidos a los léxicos bélico, lúdico, mágico, etc. Así, por ejemplo: "los codazos que nos mancharon la camiseta de sangre" (As. Com,11/07/2010), "evitó ese juego de orfebrería" (El País.com, 11/07/2010), "la Selección ahuyenta fantasmas y construye sueños" (As. com, 11/07/2010).

Existen otras formas de agrupación como la que realiza Gutiérrez (2011) que agrupa las frases de las crónicas deportivas en temas tales como: El fútbol y su filosofía, Spain is different, la figura del leñero, metáforas del balón, por demarcaciones, los periodistas, etc. Así el citado autor recoge algunas frases célebres de personajes conocidos: 
"En su vida un hombre puede cambiar de mujer, de partido político o de religión, pero no puede cambiar de equipo de fútbol" (Eduardo Galeano)

"Decir que el fútbol son 22 mercenarios dando patadas a un balón, es como decir que un violín es madera y tripa y, Hamlet, papel y tinta" (J.B. Priestley)

"Prometí que sacaría al Rotherham de la segunda división y lo logré. Bajamos a tercera" (Tommy Docherty)

"El fútbol es la recuperación semanal de la infancia" (Javier Marías)

"El fútbol es un milagro mediante el cual Europa aprendió a odiarse sin destrozarse" (Paul Auster)

Centrándonos en los ámbitos semánticos y después de una investigación bibliográfica: en la prensa italiana, Mapelli (2010); en la prensa italiana y española, Gómez Tórrego (2010) y, en la prensa española, Arroyo y García (2012), hemos encontrado que diferentes autores coinciden en señalar los siguientes ámbitos semánticos:

\begin{tabular}{l|c|c|c|}
\hline Ámbito semántico & Giovanni Mapelli & $\begin{array}{l}\text { Leonardo } \\
\text { Gómez }\end{array}$ & $\begin{array}{l}\text { Arroyo } \\
\text { García }\end{array}$ \\
\hline Épico-bélico-militar & $\mathrm{x}$ & $\mathrm{X}$ & $\mathrm{x}$ \\
\hline De la enseñanza & $\mathrm{x}$ & & $\mathrm{x}$ \\
\hline $\begin{array}{l}\text { Del espectáculo, artístico y } \\
\text { afectivo social }\end{array}$ & $\mathrm{x}$ & & $\mathrm{X}$ \\
\hline Naval y de meteorología & $\mathrm{x}$ & $\mathrm{X}$ & $\mathrm{X}$ \\
\hline Religioso y mágico & $\mathrm{x}$ & $\mathrm{X}$ & \\
\hline Erótico-amoroso & $\mathrm{x}$ & $\mathrm{X}$ & \\
\hline $\begin{array}{l}\text { Jurídico, burocrático- } \\
\text { administrativo }\end{array}$ & $\mathrm{x}$ & $\mathrm{X}$ & \\
\hline De los animales & $\mathrm{x}$ & $\mathrm{x}$ & \\
\hline De la construcción & $\mathrm{x}$ & $\mathrm{X}$ & \\
\hline De los oficios & $\mathrm{x}$ & $\mathrm{X}$ & \\
\hline De la costura & & $\mathrm{X}$ & \\
\hline $\begin{array}{l}\text { Del automóvil y de la } \\
\text { mecánica }\end{array}$ & $\mathrm{x}$ & $\mathrm{X}$ & \\
\hline Matemático-geométrico & & & \\
\hline Musical & & & \\
\hline Afectivo- lúdico & & & \\
\hline de la vida y de la muerte & & & \\
\hline
\end{tabular}

Cuadro 1 Ambitos semánticos. Elaboración propia

El objeto de esta investigación es el estudio del léxico de las crónicas deportivas de la la final de la FIFA World Cup (South Africa). Su interés radica en la singularidad y la importancia del acontecimiento en sí, constituyendo un hito de la historia del deporte y la cumbre del fútbol español. Las crónicas deportivas de fútbol alcanzan aquí también su mejor contexto para la producción textual, no solo por lo que narran, sino por el objeto que describen y las expectativas de la recepción.

El objetivo general de la investigación consiste en estudiar el carácter expresivo del léxico deportivo atendiendo a las relaciones discursivas entre: las distintas crónicas; los diferentes medios escritos, diarios generalistas y deportivos; y los ámbitos semánticos que la constituyen.

La investigación selecciona los ámbitos semánticos; define el léxico correspondiente a los cinco ámbitos seleccionados: bélico, jurídico, mágico-religioso, lúdico y social; 
distingue y clasifica la fraseología propia de lenguaje del fútbol a través de sus frases hechas, locuciones, etc.; estudia el uso que se hace de esas expresiones, diferenciando el sentido recto y referencial, del sentido figurado trópico (metafórico, metonímico, sinécdotico) que, como señala Mapelli (2004: 173): "provocan un desajuste semántico entre los constituyentes exigiéndole al público un esfuerzo de interpretación".

Consideramos estos cinco ámbitos semánticos los más adecuados para el estudio de las crónicas deportivas de la final de la FIFA World Cup (South Africa). Como se puede ver en el cuadro 1 , los autores citados estudian un gran número de ámbitos semánticos, pero no se agotan en la propuesta que hacen estos autores; sin embargo, son muchas las coincidencias entre los autores en determinados ámbitos semánticos, incluso en algunos casos coinciden los tres como es el caso de lo ámbitos: Bélico, Espectáculo-afectivo-social, Religioso-Mítico y Jurídico. Existe un ámbito, el afectivo-lúdico, que aunque solamente es citado expresamente por Gómez Tarrego (2010) y Arroyo y García (2012) sin embargo está muy presente en los tres autores de forma implícita ya que incluye las unidades léxicas del fútbol como juego.

\subsection{Los tipos de léxicos}

\subsubsection{El léxico bélico}

Existe una relación evidente y explícita entre la lucha armada y la lucha deportiva, entre los combates y los partidos de fútbol, entre las guerras y las competiciones. Como bien dice Herráez (2004: 117): "La analogía global entre la lucha armada y la lucha deportiva se impone de manera demasiado evidente para que el cronista pueda escapar a ella y encontrar en otra parte vocablos más aptos". En las crónicas deportivas se encuentran suficientes ejemplos:

"Por eso ahora la alegría es tan inmensa después de un sufrimiento tan inhumano como fue el encuentro". As. Com, 11/07/2010

"En muchos anuncios de este partido se dijo eso de la deuda histórica del fútbol con los holandeses, y la impresión que estos estaban dando es que se la querían cobrar a España a base de palos". El Mundo.es, 13/07/2010

"Aún no se sabe de dónde sacó el Pálido Iniesta esas décimas de segundo para mantener la sangre fría, bajar las pulsaciones y rematar con la derecha el balón más importante en la historia del fútbol español" Marca.com, 11/07/2010

"Casillas tuvo que apagar ante Robben otro fuego que amenazaba con quemar todas las ilusiones y los méritos españoles.”. El periodico.com, 12/07/ 2010

"irrumpieron los principales matarifes, Van Bommel y De Jong, que se sintió Karate Kid y pateó con saña el esternón de Xabi Alonso". El País.com, 11/07/2010

"Villa, quien perdía así la opción de acabar en cabeza en solitario de la tabla de artilleros". Sport.com 11/07/2010

Nuestro estudio pone de manifiesto la tensión, la lucha interna y externa, el valor que cada una de las acciones de un partido de fútbol se disputan como si fuera el último movimiento de la falange, como el último movimiento de la estrategia futbolística guerrera. Ganar es el éxito y el éxito es también una obligación. Cuando los jugadores enarbolan los trofeos y las banderas se mueven al viento, el éxito, el vencer no solo es una obligación, sino que es un honor. 


\subsubsection{El léxico jurídico}

Recoge conceptos como autoridad, poder, potestad, dominio, administración de justicia, arbitrio, garantía de derechos como marcar, firmar, decretar, defender, etc.; de deberes, cuyo incumplimento conlleva acciones de condena como la pena máxima, hacer justicia, etc. También recoge vocablos sobre los actores del entorno jurídico, tales como jueces, alguaciles, víctimas, verdugos, etc.; sobre los rituales del combate, del partido de fútbol, y del respeto que se deben vencedores y vencidos, $\mathrm{y}$, por último, sobre cuáles son los límites y las posibilidades del juego, hasta dónde llega la norma y hasta dónde se limita la creatividad a través de las reglas que impone el juego que, como bien dice Labrador (2007: 46), la violencia existente en el fútbol debe ser regulada: "Este agonismo fundante se actualiza en cada representación -en cada juego, en cada partido- permitiendo el ritual y consumándolo (...) Es necesario un discurso, un dispositivo de razón, para dominar la violencia, las pulsiones desestructuradas en el seno de una comunidad". Y esa razón debe apoyarse en una razón jurídica construida a través de las reglas del juego. Así, por ejemplo:

"Los dueños del juego son ya campeones del mundo.”. As. com, 11/07/2010.

"Holanda, cuyo número de infracciones había dado ya la vuelta al marcador." El Mundo.es, $13 / 07 / 2010$.

"El gol de Iniesta, en el segundo tiempo de la prórroga, hizo justicia con un equipo inolvidable" Marca.com, 11/07/2010.

"sin que el árbitro se enterase de la película." El periódico.com, 12/07/ 2010.

"España se vio abocada al fango, a la discusión permanente con los rivales y el alguacil británico" El País.com, 11/07/2010.

"tuvieron en sus botas de nuevo la sentencia" Sport.com 11/07/2010.

\subsubsection{El léxico lúdico}

El juego, la diversión, la obtención del placer, la utilización de reglas, la sucesión de combinaciones, las estrategias, en definitiva la relación simbólica entre ganadores y perdedores dentro de un juego. La semiótica de los torneos actualiza su léxico lúdico en la nueva semiótica del espectáculo futbolístico: “ Todo juego supone dominar la dificultad del ejercicio y elaboración. Ha de regirse por unas normas que manifiestan la conquista de un objetivo que se contabiliza a través de una marca" (Arroyo y García, 2002: 163). En las crónicas encontramos expresiones, frases y oraciones como las siguientes:

"lo que debía ser una fiesta" As. com, 11/07/2010.

"algo que no permitió encender esas luces de colores" El Mundo.es, 13/07/2010.

"España no podía practicar su juego más que a ráfagas" Marca.com, 11/07/2010

"No el que habría de competir en sutileza con el conjunto español" El periódico.com, 12/07/ 2010

"en Sudáfrica se mantienen y el grado de competitividad es abrumador." El País.com, $11 / 07 / 2010$

"el espectacular partido que cuajó en semifinales ante Alemania" Sport.com 11/07/2010 


\subsubsection{El léxico mágico}

Lo mágico es lo trascendente, lo telúrico, lo divino, la superación de todos los imposibles, la invención de todos los impedimentos. Lo mágico nace de la capacidad inventiva, incontrolable y rica de los jugadores. Las triangulaciones, la suerte basado en lo mágico y/o religioso muestra la idea de trascedencia de la implicación de lo divino que ayuda a la salvación de algunos equipos para no descender a los infiernos de la división inferior "Las invocaciones a la divinidad o las alusiones a las prácticas religiosas han llegado a ser tópicas en el discurso deportivo" (Labrador, 2007: 36). La fuerza del destino, el valor de la hazaña, de la liturgia del espectáculo "El virtuosismo muscular, tribal, nacionalista se enmarca en espectáculos litúrgicos gigantescos, magnificados por el magma televisivo" (Giner, 2003: 142-143). La suerte, la desgracia de ser crucificado en la portería. El conjunto de ritos y de prácticas donde los aficionados cantan himnos y rinden homenajes a sus héroes. El hechizo, los maleficios por los que un jugador pierde su estado de gracia. Buenos ejemplos son los siguientes:

“Qué prórroga tan eterna, tan interminable.” As. com, 11/07/2010.

"La gloria se estaba burlando del conjunto de Del Bosque" El Mundo.es, 13/07/2010.

"lo más alejado a una estrella del fútbol pero con las virtudes de un fenómeno" Marca.com, $11 / 07 / 2010$

"Un gol de Iniesta, iluminado para definir en la ocasión más importante de su vida" El periódico.com, 12/07/2010

"la epopeya que le faltaba al deporte español, que vive en la gloria tras una catarata de bienaventuranzas" El País.com, 11/07/2010

"Iniesta subió a España al cielo" Sport.com 11/07/2010

\subsubsection{El léxico social}

Lo social mira a las relaciones que se establecen entre los actores de juego y los espectadores de las gradas. Así cuando el balón es golpeado por un jugador y éste toca la portería o la roza, los espectadores de las gradas se emocionan y reaccionan con gritos de gol si "el balón besa la malla" o de "uy" si solo "acaricia el poste".

Los espectadores animan a los jugadores, les aplauden, se comportan como un único ente social, como los jugadores mismos se animan entre sí para forjar más la idea de equipo. Si bien cada equipo puede tener sus líderes, sus jugadores de referencia. En definitiva, como dice Llopis (2006: 124): "El fútbol es una actividad dotada de un tremendo potencial de creación de sentido por medio del cual proporciona a los individuos esquemas y herramientas con los que dominar las relaciones sociales y el tiempo". Lisbona, Medina y Sánchez (2006: 1), mencionando a Norbert Elias, indican cómo la actividad físico deportiva es una actividad social, total, capaz de reflejar las problemáticas y los valores sociales del momento histórico en el cuál se embarca. Veamos algunos ejemplos:

"Pocas frases tan sencillas esconden tanta historia detrás, tanta pasión, tanta felicidad, tanta alegría" As. com, 11/07/2010.

“lo de Xavi e Iniesta era un prodigio en conjunto" El Mundo.es, 13/07/2010. 
"El juego entre líneas de Iniesta y Xavi se iba imponiendo. Salió Cesc para acompañarlos" Marca.com, 11/07/2010

"Un hito en la historia del fútbol español marcado para siempre por un equipo que buscó y logró la gloria por la puerta grande" El periódico.com, 12/07/2010

"Una victoria parcial para esta irreconocible Holanda, nada que ver con el linaje de aquel equipo que tradicionalmente jugaba con el frac.” El País.com, 11/07/2010

“al sacar el remate de su ex compañero" Sport.com 11/07/2010

\section{Metodología}

\subsection{Obetivos}

1. Investigar la presencia de los ámbitos semánticos: bélico, jurídico, lúdico, mágico y social de las crónicas de fútbol.

2. Comprobar la proporcionalidad de cada uno de estos ámbitos semánticos descritos en la totalidad del discurso.

3. Analizar el discurso de las crónicas de fútbol teniendo presente los ámbitos semánticos descritos.

4. Investigar las coincidencias léxicas que se repiten en las distintas crónicas deportivas, según sean los diarios deportivos o generalistas.

5. Investigar la proporcionalidad entre el sentido recto o figurado del lenguaje deportivo de las crónicas.

6. Investigar si el comportamiento de los ámbitos semánticos en las crónicas deportivas de los diarios deportivos es similar al de los diarios generalistas.

7. Determinar la presencia de frases hechas, locuciones o expresiones y el uso de palabras tanto con valor denotativo como connotativo.

8. Detectar qué fórmula se repite con más regularidad en las crónicas deportivas, si las expresiones por agrupación de palabras o las palabras en solitario.

\subsection{Hipótesis}

1. Existe un comportamiento regular de presencia de léxicos en las crónicas deportivas indistintamente del tipo de diario al que pertenezca: deportivo o generalista.

2. La crónica deportiva se construye con más léxicos referenciales que figurados.

3. Cuando la crónica deportiva pertenece a un diario deportiva la presencia de léxicos figurados es superior a cuando pertenece a un diario generalista.

4. El lenguaje deportivo de las crónicas se construye con más vocablos que frases hechas indistintamente de que sean referenciales o figurados.

5. Los ámbitos semánticos bélico, jurídico, lúdico, mágico y social, están presentes en todo el corpus analizado con distinta presencia y orden.

6. El ámbito bélico muestra un mayor número de palabras diferentes que el resto de los ámbitos (lúdico, mágico y social), y el jurídico, un menor número.

7. Las diferencias de presencia de diferentes léxicos, vocablos o frases hechas, depende del tipo de diario al que pertenece la crónica. De manera que si la crónica pertenece a un diario deportivo, el texto se construirá con más frases hechas que si pertenece a un diario generalista. 


\subsection{Técnicas metodológicas}

\subsubsection{Corpus de análisis}

Para el estudio de los ámbitos semánticos del lenguaje de las cronistas deportivas de fútbol hemos empleado las siguientes fuentes escritas, tomando como criterio de selección los seis primeros diarios por promedio de tirada, descartando los diarios gratuitos, según el EGM del segundo trimestre de 2010 - ámbito España y target individuos con más de 14 años, fecha en las que fueron escritas las crónicas deportivas, obteniendo como muestra de análisis las crónicas deportivas de los siguientes diarios: Marca, El País, As, El Mundo, El Periódico de Catalunya y el Sport. De forma que se incluyeran las crónicas deportivas de los tres primeros diarios generalistas por promedio de tirada: El País, El Mundo y El periódico y las crónicas deportivas de los tres primeros diarios deportivos por promedio de tirada: Marca, As y Sport.

De acuerdo con ese criterio se han analizado las siguientes crónicas deportivas:

1. Marca.com, 11/07/2010, España gana su mundial en la final más dramática. Campeones del mundo de fútbol y de sufrimiento, crónica firmada por Roberto Palomar.

2. El País.com, 11/07/2010, Una España Mundial, crónica firmada por José Sámano.

3. As. com, 11/07/2010, ; Campeones del Mundo! Gracias, crónica firmada por Iniesta de Óscar García.

4. El Mundo.es, 13/07/2010, ¡Qué grande eres España! crónica firmada por Carlos E. Carbajosa.

5. El periodico.com, 12/07/2010, España alcanza la gloria ante una mísera Holanda (1-0). La prórroga hizo justicia a un equipo que fue muy superior, crónica firmada por Carlos F. Marcote.

6. Sport.com, 11/07/2010, iiiIniesta da el Mundial a España!!! Javier García de Alcaraz

Una vez elegidas las crónicas, establecimos los criterios para analizar los ámbitos semánticos bélicos, jurídicos, lúdicos, mágicos y sociales para las crónicas de la victoria de España frente a Holanda con la que obtuvo el Campeonato Mundial de Fútbol. Se realizó un análisis del discurso para cada una de las crónicas y para cada uno de los ámbitos semánticos. Una vez realizada esta tarea se clasificaron todos los léxicos señalados de acuerdo con forma de agrupamiento según fueran palabras, locuciones o frases hechas y que su sentido fuera referencial cuando relataba hechos, acontecimientos o referentes, o fuera figurado, cuando se trataba de un tropo: metáfora, metonimia o sinécdoque; conformando el siguiente corpus de léxicos: palabras, locuciones o frases hechas, siendo los resultados los que mostramos a continuación por término léxico y frecuencia de aparición en las diferentes crónicas deportivas. 


\section{Análisis de los datos}

\subsection{Análisis del léxico de las crónicas de los tres diarios deportivos}

Tabla 1 Ámbitos semánticos, léxicos y extensión de las crónicas de los tres diarios deportivos.

Fuente: Elaboración propia con los datos de la investigación. Claves: P (palabra), L (locución), F (Frase hecha), L+F (suma de palabras agrupadas, locuciones y frases) $\mathrm{T}$ (totales) y Fr (Frecuencia).

\begin{tabular}{|c|c|c|c|c|c|c|c|c|c|c|c|c|c|}
\hline \multirow{2}{*}{\begin{tabular}{|l} 
PERIÓDICOS \\
\end{tabular}} & \multirow{2}{*}{$\begin{array}{l}\text { LÉXICOS } \\
\text { PALABRAS }\end{array}$} & \multicolumn{5}{|c|}{ METÁFORAS } & \multicolumn{5}{|c|}{ REFERENCIAL } & \multirow{2}{*}{$\begin{array}{l}\text { Fr. } \\
688 \\
\end{array}$} & \multirow{2}{*}{\begin{tabular}{|c|}
$\%$ \\
100,00 \\
\end{tabular}} \\
\hline & & $\mathbf{P}$ & $\mathbf{L}$ & $\mathbf{F}$ & $\mathbf{T}$ & $\%$ & $\mathbf{P}$ & $L$ & $\mathbf{F}$ & $\mathbf{T}$ & $\%$ & & \\
\hline \multirow{7}{*}{ EL MARCA } & bélico & 3 & 7 & 2 & 12 & 31,58 & 17 & 8 & 1 & 26 & 68,42 & 38 & 5,52 \\
\hline & jurídico & 0 & 1 & 0 & 1 & 33,33 & 0 & 2 & 0 & 2 & 66,67 & 3 & 0,44 \\
\hline & lúdico & 1 & 1 & 0 & 2 & 11,76 & 15 & 0 & 0 & 15 & 88,24 & 17 & 2,47 \\
\hline & mágico & 1 & 1 & 1 & 3 & 100,00 & 0 & 0 & 0 & 0 & 0,00 & 3 & 0,44 \\
\hline & social & 1 & 6 & 2 & 9 & 32,14 & 16 & 3 & 0 & 19 & 67,86 & 28 & 4,07 \\
\hline & TOTAL LEXICOS & 6 & 16 & 5 & 27 & 30,34 & 48 & 13 & 1 & 62 & 69,66 & 89 & 12,94 \\
\hline & $\%$ AGRUPAMIENTOS & 22,22 & 59,26 & 18,52 & $L+F$ & 77,78 & 77,42 & 20,97 & 1,61 & & & & \\
\hline \multirow{8}{*}{ SPORT } & PALABRAS & $P$ & $\mathrm{~L}$ & $F$ & $T$ & $\%$ & $P$ & $\bar{L}$ & $F$ & $\bar{T}$ & $\%$ & 1004 & 100,00 \\
\hline & bélico & 20 & 7 & 2 & 29 & 53,70 & 25 & 0 & 0 & 25 & 46,30 & 54 & 5,38 \\
\hline & juridico & 2 & 3 & 0 & 5 & 41,67 & 7 & 0 & 0 & 7 & 58,33 & 12 & 1,20 \\
\hline & lúdico & 0 & 11 & 0 & 11 & 24,44 & 25 & 3 & 6 & 34 & 75,56 & 45 & 4,48 \\
\hline & mágico & 8 & 1 & 0 & 9 & 100,00 & 0 & 0 & 0 & 0 & 0,00 & 9 & 0,90 \\
\hline & social & 4 & 6 & 0 & 10 & 35,71 & 17 & 1 & 0 & 18 & 64,29 & 28 & 2,79 \\
\hline & TOTAL LEXICOS & 34 & 28 & 2 & 64 & 43,24 & 74 & 4 & 6 & 84 & 56,76 & 148 & 14,74 \\
\hline & $\%$ AGRUPAMIENTOS & 53,13 & 43,75 & 3,13 & $L+F$ & 47 & 88,10 & 4,76 & 7,14 & & & & \\
\hline \multirow{8}{*}{ AS } & PALABRAS & $\mathbf{P}$ & $\mathrm{L}$ & $F$ & $T$ & $\%$ & $\mathbf{P}$ & $\mathrm{L}$ & $F$ & $T$ & $\%$ & 1297 & 100,00 \\
\hline & bélico & 9 & 2 & 9 & 20 & 27,03 & 52 & 0 & 2 & 54 & 72,97 & 74 & 5,71 \\
\hline & jurídico & 0 & 1 & 0 & 1 & 25,00 & 3 & 0 & 0 & 3 & 75,00 & 4 & 0,31 \\
\hline & lúdico & 4 & 6 & 2 & 12 & 20,34 & 45 & 1 & 1 & 47 & 79,66 & 59 & 4,55 \\
\hline & mágico & 5 & 5 & 2 & 12 & 57,14 & 9 & 0 & 0 & 9 & 42,86 & 21 & 1,62 \\
\hline & social & 1 & 1 & 5 & 7 & 11,29 & 55 & 0 & 0 & 55 & 88,71 & 62 & 4,78 \\
\hline & TOTAL LÉXICOS & 19 & 15 & 18 & 52 & 23,64 & 164 & 1 & 3 & 168 & 76,36 & 220 & 16,96 \\
\hline & $\%$ AGRUPAMIENTOS & 36,54 & 28,85 & 34,62 & $L+F$ & 63 & 97,62 & 0,60 & 1,79 & & & & \\
\hline
\end{tabular}

De acuerdo con la tabla 1 se observa que los tres diarios deportivos analizados: $E l$ Marca, Sport y As poseen una extensión diferente para cada una de las crónicas; así la crónica del Marca utiliza 688 palabras, siendo la menos extensa por número de palabras, el As con 1297 y El Sport con 1004, son las crónicas más extensas. Se observa que existe una relación entre el número de palabras de una crónica y la densidad de sus léxicos, de manera que cuanto mayor es el número de palabras con el que se escribe la crónica, mayor es el número de vocablos de los ámbitos semánticos analizados presentes en la misma. Así el Marca con 688 palabras tiene una densidad de léxicos de los ámbitos semánticos de 89, lo que supone el 12,94\% del total; el Sport con 1004 palabras totales en la crónica tiene una densidad superior con 148 léxicos de los ámbitos semánticos, lo que representa el 14,74\% de la crónica y, por último, el $A s$ con 1297 palabras utiliza 220 léxicos de los ámbitos semánticos, lo que constituye el $16,96 \%$ de la crónica.

Todos los ámbitos semánticos están presentes en las tres crónicas. El ámbito bélico es el dominante en todas, y los demás varían de una crónica a otra en número total de léxicos, aunque observando una cierta regularidad donde prevalece el bélico, le siguen en orden el lúdico, el social, el mágico y el jurídico. Este comportamiento es el mismo tanto para el léxico referencial como para el figurado, si exceptuamos el ámbito jurídico que es superior al mágico en el referencial. Así, el ámbito bélico posee 166 léxicos entre la suma de las crónicas de El Marca, Sport y As, lo que representa 
un 5,52\%, 5,38\% y 5,71\%. Le sigue el ámbito lúdico con 121 léxicos entre las tres crónicas señaladas, repartidos entre un $2,47 \%$, un $4,48 \%$ y un $4,55 \%$. En tercer lugar, el léxico social con 118 léxicos, lo que significa un 4,07\% 4,78\% y 2,79\%. El mágico con 33 léxicos repartidos con un $0,44 \%, 0,90 \%$ y $1,62 \%$ y, finalmente, el jurídico con 19 léxicos, siendo un $0,44 \%$, un $1,20 \%$ y un $0,31 \%$.

En la suma del total de léxicos de todas las crónicas hay más presencia de léxicos referenciales que figurados. Siendo un $69,66 \%, 56,76 \%$ y 76,76 según se trate de $E l$ Marca, Sport y As. Cuando analizamos cada uno de los ámbitos semánticos por separado observamos que se mantiene la tendencia general y poseen más léxicos referenciales que figurados, excepto el bélico en la crónica del Sport donde es ligeramente superior el figurado $(53,70 \%)$, y el ámbito mágico que posee más léxicos figurados que referenciales.

Los agrupamientos de palabras del lenguaje periodístico del fútbol repiten la misma fórmula con regularidad. Prevalece la palabra frente a la locución y la frase en el léxico referencial tanto en frecuencia $(48,74,164)$ como en porcentajes $(77,42 \%$, $88,10 \%$ y $97,62 \%$ ) y para todas y cada una de las crónicas. Por el contrario, prevalecen los agrupamientos de palabras a través de la suma de locuciones y frases tanto en frecuencias absolutas $(21,30,33)$ como en porcentajes $(77,78 \%, 47 \%$ y $63 \%)$ en el léxico metafórico de las tres crónicas. Tan solo en la crónica del Sport prevalece ligeramente la palabra $(53,13 \%)$ sobre la locución y la frase $(43,75 \%$ y $3,13 \%)$.

En resumen, las crónicas de los diarios deportivos tienen un comportamiento regular, de manera que cuanto mayor es el número de palabras con el que se escriben, mayor es el número de léxicos semánticos. Todos los ámbitos semánticos están presentes en las tres crónicas. El ámbito bélico es el dominante y le siguen en orden el lúdico, el social, el mágico y el jurídico. Hay más presencia de léxicos referenciales que figurados. En el léxico referencial prevalece la palabra frente a la locución y la frase hecha, mientras que en el léxico metafórico prevalecen las locuciones y las frases hechas frente a las palabras.

\subsection{Análisis del léxico de las tres crónicas de los diarios generalistas}

Tabla 2. Ámbitos semánticos, léxicos y extensión de las crónicas de los 3 diarios de generalistas. Fuente: Elaboración propia con datos de la investigación. Claves: P (palabra), L (locución), F (Frase hecha), L+F (suma de palabras agrupadas, locuciones y frases), T (totales) y Fr (Frecuencia).

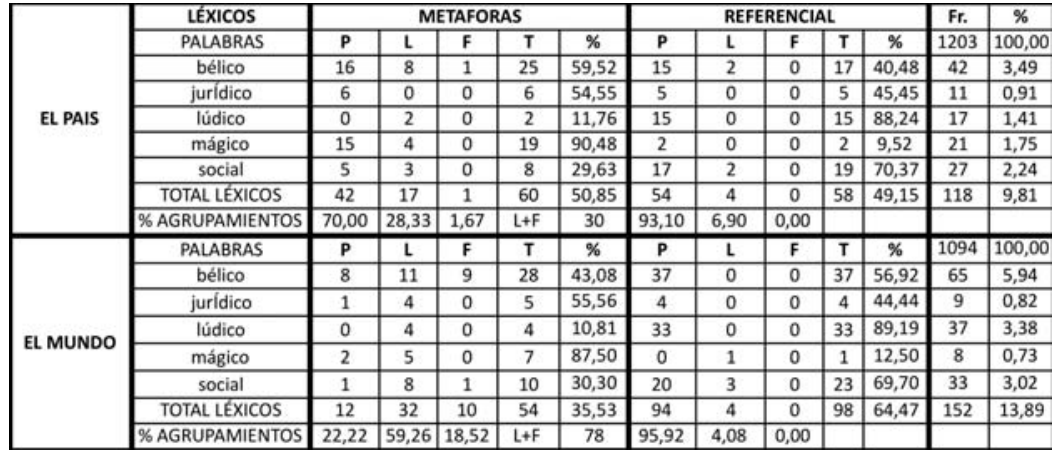




\begin{tabular}{|c|c|c|c|c|c|c|c|c|c|c|c|c|c|}
\hline \multirow{8}{*}{ EL PERIODICO } & PALABRAS & $\mathbf{P}$ & $\mathrm{L}$ & $\mathbf{F}$ & $T$ & $\%$ & $P$ & $\mathrm{~L}$ & $\mathrm{~F}$ & \begin{tabular}{|c|c|}
$T$ \\
\end{tabular} & $\%$ & 698 & 100,00 \\
\hline & bélico & 10 & 3 & 2 & 15 & 25,00 & 45 & 0 & 0 & 45 & 75,00 & 60 & 100,00 \\
\hline & jurídico & 0 & 0 & 0 & 0 & 0,00 & 3 & 0 & 0 & 3 & 100,00 & 3 & 0,43 \\
\hline & lúdico & 1 & 4 & 0 & 5 & 10,87 & 40 & 1 & 0 & 41 & 89,13 & 46 & 6,59 \\
\hline & mágico & 4 & 0 & 1 & 5 & 62,50 & 2 & 1 & 0 & 3 & 37,50 & 8 & 1,15 \\
\hline & social & 3 & 1 & 0 & 4 & 25,00 & 11 & 1 & 0 & 12 & 75,00 & 16 & 2,29 \\
\hline & TOTAL LÉXICOS & 18 & 8 & 3 & 29 & 21,80 & 101 & 3 & 0 & 104 & 78,20 & 133 & 19,05 \\
\hline & \% AGRUPAMIENTOS & 62,07 & 27,59 & 10,34 & $L+F$ & 38 & 97,12 & 2,88 & 0,00 & & & & \\
\hline
\end{tabular}

De acuerdo con la tabla 2 se observa que los tres diarios de información general analizados: El País, El Mundo y El Periódico poseen una extensión diferente para cada una de las crónicas; así la crónica del El Periódico utiliza 698 palabras, siendo la menos extensa por número de palabras, El País con 1203 y El Mundo con 1094, son las crónicas más extensas. Se observa que no existe una relación entre el número de palabras de una crónica y la densidad de sus léxicos. Así el Periódico con 698 palabras tiene una densidad de léxicos de los ámbitos semánticos de 133, lo que supone el 19,05\% del total; el Mundo con 1094 palabras totales en la crónica tiene una densidad superior con 152 léxicos de los ámbitos semánticos, lo que representa el 13,89\% de la crónica y, por último, El País con 1203 palabras utiliza 118 léxicos de los ámbitos semánticos, lo que constituye el 9,91\% de la crónica.

Todos los ámbitos semánticos están presentes en las tres crónicas. El ámbito bélico es el dominante en todas y los demás varían de una crónica a otra en número total de léxicos, aunque observando una cierta regularidad donde prevalece el bélico, le siguen en orden el lúdico, el social, el mágico y el jurídico. Este comportamiento no es el mismo según nos fijemos en el léxico referencial, idéntico al de puntuaciones totales con la excepción del jurídico que prevalece sobre el mágico, o en el figurado donde el orden de frecuencia de léxicos es bélico, mágico, social y en igualdad lúdico y jurídico. Así, el ámbito bélico posee 167 léxicos entre la suma de las crónicas de El País, El Mundo y El Periódico, lo que representa un 3,49\%, 5,94\% y 8,60\%. Le sigue el ámbito lúdico con 100 entre El País, El Mundo y El Periódico, repartidos entre un 1,41\%, un 3,38\% y un 6,59\%. En tercer lugar el léxico social con 76 en las crónicas El País, El Mundo y El Periódico, lo que significa un 2,24\% 3,02\% y 2,29\%. El mágico con 37 léxicos repartidos con un $1,75 \%, 0,73 \%$ y $1,15 \%$ y, finalmente, el jurídico con 23 léxicos, siendo un $0,91 \%$, un $0,82 \%$ y un $0,43 \%$, según El País, El Mundo y El Periódico.

En la suma del total de léxicos de todas las crónicas hay más presencia de léxicos referenciales que figurados. Siendo un $49,15 \%, 64,47 \%$ y 78,20 según se trate de $E l$ País, donde es muy ligeramente inferior, El Mundo y El Periódico. Cuando analizamos cada uno de los ámbitos semánticos por separado observamos un comportamiento desigual. De manera que es superior en las tres crónicas el léxico referencial de los ámbitos lúdico y social y en el léxico figurativo el ámbito mágico, el resto de los ámbitos bélico y jurídico dependen de la crónica. Así el bélico referencial tiene mayor presencia porcentual en las crónicas de El Mundo y El Periódico y el jurídico en la de El Periódico. Por el contrario tienen mayor presencia porcentual el bélico figurativo en El País y el jurídico figurativo en El Mundo y El País.

Los agrupamientos de palabras del lenguaje periodístico del fútbol repiten la misma fórmula. Prevalece, en general, la palabra frente a la locución y la frase tanto en el léxico referencial como en el figurativo, en el lenguaje referencial tanto en frecuencia 
$(54,94,101)$ como en porcentajes $(93,10 \%, 95,92 \%$ y $97,12 \%)$ y con alguna pequeña variación para el léxico figurativo en frecuencias $(42,12,18)$ como en porcentajes(70 $\%, 22,22 \%$ y $62,07 \%$ ) donde solo El Mundo invierte esta tendencia.

En resumen, no existe una relación entre el número de palabras de una crónica y la densidad de sus léxicos. El ámbito bélico es el dominante en todas las crónicas y le siguen en orden el lúdico, el social, el mágico y el jurídico; en el léxico referencial, el jurídico prevalece sobre el mágico y, en el figurado, el mágico sobre el jurídico. Hay más presencia de léxicos referenciales que figurados. Es superior el léxico referencial en los ámbitos lúdico y social y el léxico figurativo en el ámbito mágico. Prevalece, en general, la palabra frente a la locución y la frase tanto en el léxico referencial como en el figurativo.

\section{Conclusiones}

Se confirma la primera hipótesis en los diarios deportivos ya que existe una relación entre el tamaño de una crónica deportiva y la densidad de sus distintos tipos de léxicos, bélico, jurídico, lúdico, mágico y social, pero no se confirma cuando se trata de diarios generalistas.

Se confirma la segunda hipótesis tanto para los diarios deportivos como para los generalistas ya que existen más léxicos referenciales que figurados.

No se cumple la tercera hipótesis que marca diferencias en el uso del lenguaje figurado superior de los diarios deportivos frente a los generalistas, ya que la investigación pone de manifiesto un comportamiento similar en el uso de tropos.

Se confirma la hipótesis cuarta para el léxico referencial donde prevalece la palabra frente a la locución y la frase hecha en todas las crónicas tanto para los diarios generalistas como para los deportivos. No se confirma esta hipótesis para el léxico figurativo de los diarios generalistas.

Se confirma la quinta hipótesis ya que los ámbitos semánticos bélico, jurídico, lúdico, mágico y social, están presentes en todo el corpus analizado con distinta presencia y orden.

Se confirma la sexta hipótesis pues el ámbito bélico tiene mayor frecuencia y mayor diversidad léxica tanto en las crónicas de los diarios deportivos como en las de los diarios generalistas. Se confirma que el ámbito jurídico es el de menor frecuencia de léxicos en los periódicos generalistas, pero no en los periódicos deportivos.

Se confirma la séptima hipótesis de manera que cuando la crónica pertenece a un diario deportivo, el texto se construye con más frases hechas que cuando pertenece a un diario generalista, tanto para el lenguaje referencial como para el metafórico.

\section{Discusión}

La investigación fundada en datos nos ha llevado a las conclusiones señaladas anteriormente, sin embargo consideramos que es preciso hacer una reflexión crítica sobre las razones del comportamiento textual de las crónicas deportivas y su mensaje periodístico.

La crónica periodística exige al menos una información mínima del acontecimiento y del espectáculo en cuanto que es relato y como señala Casals (2001) "el secreto para escribir un buen reportaje, un buen relato, no es otro que el saber narrar". Por eso en 
todas las crónicas deportivas prevale el lenguaje referencial, el uso de palabras frente al uso de locuciones y frases hechas, como es propio en sí de toda crónica de un decir de lo que acontece en el tiempo. El tamaño de la crónica permite detenerse en una narración pormenorizada y alusiva a los léxicos específicos del lenguaje futbolístico, por lo que cuando se dispone de una mayor extensión en la crónica, crece la presencia de esos léxicos específicos: bélico, lúdico, social, mágico y jurídico. Este aspecto favorece, no solamente la presencia de más léxicos, sino también de más recursos estilísticos que a la postre van a configurar el estilema de autor de cada periodista. Y con ello dignifica literariamente a la crónica deportiva como recuerda Casals (2001) citando a Manuel Vicent.

¿Pero existe un estilema propio que dé razón de la forma en que se organizan las crónicas dependiendo de su pertenencia a periódicos deportivos o periódicos generalistas?

Nuestra tesis es que sí existe un modelo textual implícito de crónica futbolística, especialmente para los diarios deportivos, que se caracteriza por utilizar de forma proporcionada el lenguaje futbolístico en función del tamaño de la crónica, lo que significa, independientemente de lo que acontezca en el terreno de juego, que existe un patrón de discurso que utiliza palabras, locuciones y frases hechas del lenguaje futbolístico de cada uno de los ámbitos semánticos analizados (bélico, lúdico, social, mágico y jurídico), donde siempre prevalece el léxico bélico sobre todos los demás. Cuando la crónica deportiva describe los acontecimientos lo hace a través de un discurso referencial donde abundan las palabras como unidad ya que este lenguaje es propicio para contar los hechos tal como fueron, mientras que cuando pretende transmitir emociones, embellecer el lenguaje, organizar creativamente el discurso utiliza el lenguaje retórico de los tropos, privilegiando las locuciones y las frases hechas que se convierten en patrimonio de los discursos futbolísticos, haciendo propio un discurso que se va enriqueciendo con cada innovación, alimentada por las aportaciones de la imaginación del periodista.

La pregunta que nos hacemos es si la metáfora no llevará implícito también un alto carácter referencial (Ricoeur, 2001; García, 2007; Davidson, 1978; Wheel Wright, 1979), y si como también defiende Paul Ricoeur en la Metáfora Viva (2001), cualquier metáfora no nos permite descubrir nuevas perspectivas de la realidad, pero incluso también lo contrario, si cualquier referencia periodística a la realidad no está haciendo ya la construcción social de la misma en cuanto que está utilizando una retórica informativa como M. Elvira Teruel Planas (1997) indica en su libro Retòrica, Informació i Metàfora en su análisis aplicado a los medios de comunicación de masas.

En las crónicas deportivas de los diarios generalistas prevalece la información sobre la creación y, por tanto, se usa con más frecuencia palabras que locuciones o frases tanto en el lenguaje referencial como en el figurado. Además destaca el ámbito jurídico frente al ámbito mágico por la propia prevalencia de lo informativo, y cuando aparece lo mágico se transmite a través de un lenguaje figurado transido de frases hechas y locuciones que responden en parte a la naturaleza de este ámbito semántico.

Las crónicas deportivas no sólo narran los acontecimientos del terreno de juego, sino que también describen las relaciones empáticas que se producen en las gradas, en relación con el desarrollo del partido, el ánimo a los propios jugadores de su equipo, los abucheos al equipo contrario, la explosión de júbilo con la victoria, la enorme de- 
cepción de la derrota, las luchas entre los partidarios de un equipo u otro, y lo hacen con los dos tipos de lenguaje referencial y figurado. Quién narra, quién escribe las crónicas de los acontecimientos deportivos está también aludiendo a modelos sociales y a la construcción social de la realidad. Lo que están indicando los ámbitos léxicos es la relación entre las funciones del juego y el reflejo social, así la lucha que se establece entre dos equipos está indicada por el léxico bélico y simbólicamente representa a los seguidores de los equipos, las ciudades a las que pertenecen y las identidades que se conforman. El ámbito jurídico significa la reglas del juego que se deben cumplir para que esas relaciones de lucha en el juego esté controlada por normas y reglamentos como en la misma realidad social. El ámbito lúdico muestra la alegría del juego, la invención, la creatividad, el construirse e inventarse jugando. El ámbito mágico es señal de la superación, de una estética de los mejor, de la consecución de objetivos a veces incluso por encima de sus posibilidades. El ámbito social muestra el campo de las relaciones de los equipos, de los jugadores de los propios equipos, de la respuesta de las gradas y de la empatía que un público encuentra con un equipo ya sea en la victoria o en la derrota, el equipo es la ciudad, la ciudad alude a lo social y se está ganando o perdiendo cuando el equipo local lucha por evitar lo peor, mantener el estatus adquirido o aumentar su presencia e identidad en el mundo y en los medios de comunicación.

\section{Referencias bibliográficas}

ARROYO ALMARAZ, Isidoro y GARCÍA GARCÍA, Francisco (2002): Lengua Castellana y Literatura con El deporte. Madrid, Ediciones del Laberinto.

ARROYO ALMARAZ, Isidoro y GARCÍA GARCÍA, Francisco (2012): “Análisis de las crónicas deportivas de la fase final del mundial de fútbol ganado por España" (en prensa).

CASALS CARRO, María Jesús (2001): "La narrativa periodística o la retórica de la realidad construida". Estudios sobre el mensaje periodístico, vol. 7, pp. 195-219. Madrid, Servicio de Publicaciones de la Universidad Complutense.

CASALS CARRO, María Jesús (2004): "La opinión en la prensa: retrato de España en el primer año del siglo XXI". Estudios sobre el Mensaje Periodístico, vol. 10, pp. 9-66. Madrid, Servicio de Publicaciones de la Universidad Complutense.

CASTAÑÓN RODRÍGUEZ, José Ramón (1993): El lenguaje periodístico del fútbol. Valladolid, Secretariado de Publicaciones de la Universidad, p. 202.

DAVIDSON, Donald (1978): "What metaphors mean" en Critical Inquiry, 5.

GARCÍA GARCÍA, Francisco (2007): "Una retórica de la publicidad: de la narrativa inventiva a la verdad metafórica". Pensar la Publicidad, Vol 1, 2, 167-182.

GINER, Salvador (2003): Carisma y razón. La estructura moral de la sociedad moderna. Madrid, Alianza Editorial.

GÓMEZ TORREGO, Leonardo (2010): “Aspectos semánticos del Lenguaje del Fútbol en España". En: monográficos marcoELE, n 11, pp.150-158. 
GUTIÉRREZ, Miguel (2011): Frases de fútbol. Barcelona, Libros del Atril.

HERRÁEZ PINDADO, Ángel Javier (2004): "La metáfora en la formación del vocabulario del ciclismo en francés". Ibérica, vol. 7, pp. 107-123.

LABRADOR MÉNDEZ, Germán (2007): "Cuando ataca Ronaldo ataca una manada. El discurso del fútbol en los media actuales como discurso épico (Estructuras, formas y funciones comparadas)". Culturas Populares. Revista Electrónica, 4, pp.150.

LISBONA GUILLÉN, Miguel; MEDINA, Francisco Xavier y SÁNCHEZ, Ricardo (2006): "Los orígenes de la Antropología del Deporte". Revista Pueblos y Fronteras Digital, vol. 2, pp.1-12.

LLOPIS GOIG, Ramón (2006): "El fútbol como ritual festivo. Un análisis referido a la Sociedad Española". Anduli. Revista Andaluza de Ciencias Sociales, nº, 6, p.115132.

MAPELLI, Giovaani (2004): "Locuciones del lenguaje del fútbol". En: Centro Virtual Cervantes (consultado el 02/03/2012 en: http://cvc.cervantes.es/literatura/aispi /pdf/18/18_169.pdf)

MAPELLI, Giovanni (2010): “Ámbitos Semánticos del Lenguaje del Fútbol en Italia”. monográficos marcoELE, $\mathrm{n}^{\mathrm{o}} 11$, pp.159-172.

MEDINA MONTERO, J. Francisco (2005): "La metáfora en el léxico futbolístico: el caso de los participantes en español, y sus posibles equivalentes en italiano". En Léxico Español actual. Actas del I Congreso Internacional de Léxico Español Actual. Venecia-Treviso, Università Ca' Foscari Venezia.

RICOEUR, Paul (2001): "La metáfora viva". Madrid, Ediciones Cristiandad.

SANTA CRUZ, Eduardo (2011): "Prensa y modernización en América Latina y Chile en la segunda mitad del siglo XIX: la crónica y los cronistas". Estudios sobre el mensaje periodístico, 647, Vol. 17, Núm. 2, pp. 647-660. Madrid, Servicio de Publicaciones de la Universidad Complutense.

SANTAMARÍA, Luisa (1995): "El léxico del fútbol en los periódicos". Estudios sobre el mensaje periodístico, vol $^{\circ}$ 2, pp. 151-153. Madrid, Servicio de Publicaciones de la Universidad Complutense.

TERUEL PLANAS, M. Elvira (1997): Retòrica, informació i Metàfora. Universitat Autònoma de Barcelona, Publicacions de la Universitat Jaume I, Universitat de València, Aldea Global.

WHITE HAYES, Michael (2001): "Metaphor and Metonymy in thought and expression" En: AGUADO DE CEA, Guadalupe y DURÁN ESCRIBANO, Pilar (coords.): La investigación en lenguas aplicadas: enfoque multidisciplinary. Madrid, Fundación Gómez-Pardo. p. 47-63. 